\title{
LA NUEVA RETÓRICA*
}

La publicación de un tratado consagrado a la argumentación y su relación con una vieja tradición, la de la retórica y la dialéctica griegas, constituye una ruptura con la concepción de la razón y del razonamiento según Descartes.

En efecto, a nadie se le ocurrirá negar que el poder de deliberar y de argu. mentar no es un signo distintivo del ser razonable. $Y$, sin embargo, el estudio de los medios de prueba utilizados para obtener la adhesión ha sido olvidado durante tres siglos por los lógicos y los teóricos del conocimiento. Este hecho se debe a que en los argumentos no hay un poder coercitivo que obligue forzosamente al apoyo de una tesis. La naturaleza misma de la deliberación y de la argumentación se oponen a la necesidad y a la evidencia, porque no se delibera allí donde la solución se presenta como necesaria y no se argumenta contra la evidencia. El dominio de la argumentación es el de lo verosímil, lo plausible, lo probable, en la medida en que esto último escapa a la certidumbre de cálculo. Ahora bien, la concepción netamente expresada por Descartes en la primera parte de su Discurso del método era la considerar "casi como falso todo lo que eran tan sólo verosímil". Descartes hizo de la evidencia la característica de la razón, y no quiso considerar como racionales más que las demostraciones que parten de ideas claras y distintas y que se derivan mediante pruebas apodícticas, consiguiendo la evidencia característica de los axiomas.

La primera parte de este libro está dedicada a los cuadros de la argumentación. La argumentación apunta a la adhesión de los espíritus y por este hecho mismo supone la existencia de un contacto intelectual. La formación de una comunidad efectiva de los espíritus exige un conjunto de condiciones. $\mathrm{El} \mathrm{minimum} \mathrm{indis-}$ pensable para la argumentación es la existencia de un lenguaje común, de una técnica que permita la comunicación.

Los autores dedican nada menos que treinta páginas al análisis de los diversos tipos de auditorio y de la relación del orador con éste. $\mathrm{O}$ bien de los diversos tipos de lectores y de la relación que el escritor guarda con ellos.

En este sentido se define el auditorio como el conjunto de aquellos sobre los cuales el orador quiere influir mediante su argumentación. Hay auditorios particulares, como, por ejemplo, los miembros de un tribunal a quienes se dirige el orador abogado. Y hay lo que se llama el auditorio universal al cual se dirige el filósofo. El orador toma en cuenta las características propias del auditorio al cual se dirige. El ideal sería poder contar con un auditorio compuesto por seres inteligentes y razonables. La búsqueda de una objetividad, cualquiera que sea su índole, corresponde a este ideal, a este deseo de trascender las particularidades históricas o locales,

* Traité de CArgumentation: La Nouvelle Rhétorique, por Ch. Perelman y L. OlbrechsTyteca, $2^{*}$ edición, Colection de sociologie générale et de philosophie sociale. Editions de l'Institut de Sociologie. Université Libre de Bruxelles, 1970. 
de modo que las tesis defendidas puedan ser admitidas por todos. Muchísimas veces la finalidad del orador consiste en convencer para un determinado tipo de acción. Cuando es así, asistimos a la repetición del debate secular entre los partidarios de la verdad y los de la opinión, entre filósofos, buscadores de lo absoluto y retóricos empeñados en la acción.

Estudian los autores la argumentación ante un solo auditor. El alcance filosófico de la argumentación presentada a un solo auditor y su superioridad sobre aquella dirigida a un vasto auditorio han sido admitidas por todos los que, en la Antigüedad, proclamaban el primado de la dialéctica en contraste con la retó. rica. Ésta se limita a la técnica de un largo discurso continuado. Pero tales discursos, con toda la acción oratoria que ellos implican, resultarian ridículos $\mathbf{e}$ ineficaces ante un sólo auditor. Es normal tomar en cuenta las reaccion'es del auditorio, sus negaciones y sus titubeos. Tan pronto como se los verifica, el orador tiene que esforzarse en probar el punto contestado, en informarse de las razones de la resistencia del interlocutor, en penetrar el sentido de sus objeciones: el discurso se convierte en diálogo.

Estudian los autores también la deliberación consigo mismo y advierten que el sujeto que delibera está considerado a menudo como una encarnación del auditorio universal. La finalidad de toda argumentación es el provocar o acrecentar la adhesión de los espíritus a las tesis que se presentan a su asentimiento: una argumentación eficaz es aquella que logra acrecentar esta intensidad de adhesión a modo de disparar en los auditores la acción propuesta.

La elocuencia práctica, que comprendía el género judicial y la deliberación política, era el campo de predilección en el cual se enfrentaban abogados y politicos que defendían, argumentando, dos tesis opuestas y a veces incluso contradictorias, tratando cada uno de los argumentadores de obtener la adhesión de su auditorio. En los puntos controvertidos, el pro y el contra encontraban a menudo defensores igualmente hábiles y honorables.

La retórica digna del filósofo, nos dice Platón en el Fedro, es la que ganaría por sus razones incluso a los dioses y debería colocarse bajo el signo de la verdad. Veinte siglos más tarde Leibniz, quien se da cuenta de que el saber humano es limitado e incapaz a veces de suministrar pruebas suficientes de la verdad de todo aserto, desearía por lo menos que el grado de asentimiento conseguido a cualquier tesis sea proporcional a lo que enseña el cálculo de las probabilidades y de las presunciones.

Se ocupa después del discurso epidíctico, por ejemplo, la oración funeraria, el elogio de una persona, etc. Trata después del tema de la educación y de la propaganda viendo entre ambas una diferencia tajante.

La segunda parte de este libro está dedicada al punto de partida de la argumentación y empieza ocupándose del acuerdo previo y del acuerdo que se logre después de verificada la argumentación.

En cuanto a los tipo de acuerdo que desempeñan diferentes papeles en el pro- 
ceso argumentativo, los clasifica en dos categorías: la una relativa a lo real que se refiere a los hechos, las verdades y las presunciones; la otra relativa a lo preferente que contiene los valores, las jerarquías y los tópicos de lo preferente.

Lo real se caracteriza por una pretensión de validez para un auditorio universal. Por el contrario, lo que atañe a lo preferible está ligado a un punto de vista determinado que tiene que identificarse con el de un auditorio particular; pero los hechos reales quedan sustraidos a la argumentación porque suscitan una adhesión general de un auditorio universal, la cual no necesita ser reforzada ni justificada. Si se hace necesario justificar un hecho real mediante un proceso argumentativo, entonces ese hecho pierde su condición de premisa privilegiada y se convierte en una conclusión de un proceso argumentativo; pero deja de ser una premisa incontestada.

Se designa con el nombre de verdades al sistema de hechos y a los complejos relativos a enlaces entre hechos, lo mismo si se trata de teorías cientificas o de concepciones filosóficas o religiosas que trascienden la experiencia.

Además de los hechos y las verdades, todos los auditorios admiten presunciones las cuales disfrutan de un acuerdo universal. Sin embargo, las presunciones son susceptibles de ser reforzadas, en un cierto momento, por otros elementos. Veamos algunos ejemplos de presunciones de uso corriente: la presunción de que la cualidad de un acto manifiesta la de la persona que lo ha ejecutado; la presunción de credulidad natural que hace que nuestro primer movimiento sea el de acoger como verdadero lo que se nos dice y que además ha sido generalmente admitido, cuando no hay razones especiales de desconfianza; la presunción de interés, según la cual concluimos que todo enunciado, puesto a nuestro conocimiento, es considerado como interesante; la presunción concerniente al carácter sensato de toda acción humana; la presunción de que para cada categoría de hechos y principalmente para cada categoría de comportamiento hay un aspecto considerado como normal, que puede servir de base a los razonamientos. Se trata respecto de esta última de la presunción, salvo prueba en contrario, de que lo normal es lo que se ha producido o se producirá. Lo normal es lo habitual en un grupo, aunque esta categoría sea muy inestable.

Al lado de los hechos, de las verdades y de las presunciones, caracterizadas por el acuerdo del auditorio universal, hay que hacer lugar en este inventario de tipos de premisas, a objetos a propósito de los cuales se pretende tan sólo la adhesión de grupos particulares. Se trata de los valores, las jerarquías y los tópicos de lo preferible.

En los dominios jurídico, político y filosófico, los valores intervienen como base de la argumentación a lo largo de todo el desarrollo argumentativo. Se hace apelación a los valores para comprometer al auditor a que haga ciertas elecciones más bien que otras, $y$, sobre todo, para justificar tales elecciones, a manera de convertirlas en aceptables y aprobadas por los demás. En una discusión no es posible sustraerse a la apelación a los valores, negando éstos pura y simplemente. 
Si se rechazan todos los valores, nos encontrariamos bajo el dominio de la fuerza y fuera del campo de la discusión. A condición de no especificar su contenido, los valores pueden ser válidos para un auditorio universal. Pero a partir del momento en que intentamos precisar su sentido, su contenido y su alcance, encontraremos solamente la adhesión de auditorios particulares. Mientras que la moral occidental, en la medida en que se inspira en concepciones grecorromanas, atribuye sobre todo un premio a la observación de reglas válidas para todos y en todas las circunstancias, hay comportamientos y virtudes que no pueden concebirse más que por relación a valores concretos. Las nociones de fidelidad, lealtad, solidaridad, disciplina son de esta especie. De hecho, cualesquiera que sean los valores dominantes en un cierto medio de cultura, la vida del espíritu no puede evitar el tomar apoyo tanto sobre valores abstractos como sobre valores concretos.

La argumentación toma como apoyo no solamente valores abstractos y concretos, sino también igualmente jerarquías tales como las siguientes: la superioridad de los hombres sobre los animales, y de los dioses sobre los hombres. Sin duda estas jerarquias serían justificables con la ayuda de los valores; pero frecuentemente las jerarquías quedan implícitas, tales como la jerarquía entre personas y cosas, en aquel pasaje en el cual Scheler, habiendo mostrado que los valores pueden jerarquizarse según sus sustratos, concluye que por su misma naturaleza los valores relativos a las personas son superiores a los valores relativos a las cosas. Hay jerarquías concretas como las mencionadas; pero las hay también abstractas como por ejemplo la superioridad de lo justo sobre lo útil. Las jerarquías de los valores son más importantes, desde el punto de vista de la estructura de una argumentación, que los valores mismos. Hay algunos que prefieren la exactitud y precisión del conocimiento de un punto humilde e intrascendente al intento de conocer algo de índole superior. La tesis contraria, es decir, la atribución de una mayor importan. cia a una opinión razonable sobre temas útiles, mucho más que sobre las inutilidades de los conocimientos exactos, fue sostenida por Isócrates y por Santo Tomás.

Es necesaria la jerarquización de los valores por virtud de que la persecución simultánea de esos valores crea incompatibilidades y obliga a una elección. Cuando se trata de fundar valores o jerarquías, se puede también recurrir a premisas de orden muy general, que Perelman llama lugares, es decir, los tópicos, consagrados al razonamiento dialéctico. Para los antiguos, probablemente con el propósito de ayudar el esfuerzo de invención del orador, los tópicos designaban rúbricas bajo las cuales se podía clasificar los argumentos. Se trataba de agrupar con el fin de encontrar más fácilmente, en caso de precisión, el material necesario. De aquí la definición de los tópicos como almacenes de argumentos. Aristóteles distinguía entre tópicos comunes, que pueden servir indiferentemente en cualquier ciencia y que no pertenecen específicamente a ninguna, y tópicos específicos que son propios sea de una ciencia particular, sea de un género oratorio bien definido.

Primitivamente, los lugares o tópicos comunes se caracterizaban por su gran 
generalidad que los hacía utilizables en todas las circunstancias. Los lugares comunes de nuestros dias se caracterizan por una banalidad que no excluye en moda alguno la especificidad. $Y$ no se reconoce su valor argumentativo. Se tiene la tendencia a olvidar que los lugares o tópicos comunes forman un arsenal indispensable en el cual tendrá que beber quien quiera persuadir a otro. Aristóteles estudia en sus tópicos toda especia de lugares que puedan servir de premisa a silogismos dialécticos o retóricos; y. los clasifica, según las perspectivas establecidas por su filosofia, en tópicos del accidente, del género, de lo propio, de la definición y de la identidad. Pero el propósito de Perelman es diferente. Por una parte, no quiere ligar su punto de vista a una metafísica particular; y, por otra parte, como distingue los tipos de objeto concernientes a lo real, de aquellos que conciernen a lo preferible, llama tópicos solamente a las premisas de orden general que permiten fundar valores y jerarquías y que Aristóteles estudia entre los tópicos del accidente. Estos tópicos constituyen las premisas más generales, a menudo sobrentendidas, que intervienen para justificar la mayor parte de nuestras elecciones. Cuando se verifica un acuerdo, podemos presumir que está fundado sobre los tópicos más generales admitidos por los interlocutores. Sin embargo, para indicarlos, sería preciso recurrir a hipótesis que no son nada menos que ciertas. Así se creería uno autorizado quizá a referir la afirmación de que lo que es más durable y más estable es preferible a aquello que lo es menos, a un tópico que parece más general, el de la superioridad del todo sobre la parte.

Tiene en efecto un indudable interés el examen de los tópicos más particulares que prevalecen en diversas sociedades. Todos los auditorios, cualesquiera que ellos sean, toman en cuenta tópicos agrupados bajo algunas rúbricas muy generales: tópicos de la cantidad, de la cualidad, del orden, de lo existente, de la esencia, de la persona. Se entiende por tópicos de la cantidad los lugares comunes que afirman que alguna cosa vale más que otra por razones cuantitativas. Aristóteles señala alguno de esos tópicos: un número más grande de bienes es preferible a un número menos grande; el bien que sirve a un número más grande de fines es preferible a aquel que no es útil en el mismo grado; lo que es más durable y estable es preferible a lo que lo es menos. Para Isócrates, el mérito es proporcional a la cantidad de personas a las cuales se presta servicio; los atletas son inferiores a los educadores, porque son ellos solos los que se benefician de su fuerza, mientras que los educadores son provechosos para todos. Es el mismo argumento que utiliza Timon para valorar el folleto: "El creador habla a los diputados; el publicista a los hombres de Estado; el periódico a sus suscriptores; el folleto a todo el mundo... Donde el libro no penetra, llega el periódico. Donde el periódico no llega, el folleto circula."

"El todo vale más que la parte" parece transponer en términos de preferencia el axioma "el todo es más grande que la parte". Incluso Bergson, cuando se propone establecer la superioridad del devenir, de la evolución, sobre lo cristalizado y lo estático, no titubea en utilizar el tópico de la cantidad. 
Y también Platón, cuando opone la verdad a la opinión del gran número, lo hace, sin embargo, con la ayuda de un tópico de la cantidad, que valora la verdad, haciendo de ella un elemento de acuerdo de todos los dioses, y que debería suscitar el de todos los hombres. El tópico cuantitativo de lo durable permite también valorar la verdad como lo que es eterno por contraste con las opiniones inestables y pasajeras.

Otro tópico de Aristóteles afirma que "es también más deseable lo que es más útil en toda ocasión o en la mayoría de los tiempos; por ejemplo, la justicia y la templanza son preferibles a la valentía, porque las dos primeras son siempre útiles, mientras que la valentía lo es tan sólo en ciertos momentos".

Rousseau gusta de razonamientos de esa especie. Sobre parejas consideraciones de universalidad funda la superioridad de la educación que él preconiza, basada "en el orden social, donde todos los lugares están marcados, cada uno debe ser educado para el suyo. Si un particular formado para su lugar sale de él, ya no sirve para nada... En el orden natural los hombres, siendo todos iguales, su vocación común es el estado de hombre; y quien quiera que está bien educado para tal estado no puede cumplir mal lo que se refiere al mismo... Es necesario, pues, generalizar nuestras concepciones y considerar en nuestro alumno al hombre abstracto. El hombre expuesto a todos los accidentes de la vida humana".

Para justificar la preferencia del bien sobre la valentía, Aristóteles dice: "es preferible. .. de las dos cosas aquella que si la posee todo el mundo suprimiría la necesidad de la otra... ; si todo el mundo fuese justo, la valentía no serviría para nada, mientras que si todo el mundo fuese valiente, la justicia seguiría siendo útil".

Cicerón agrupa bajo la rúbrica de la eficacia (vis) los tópicos siguientes: "Ia causa eficiente prevalece sobre aquella que no lo es; las cosas completas por sí mismas son preferibles a aquellas que tienen necesidad del concurso de otras cosas; aquellas que están en nuestro poder son preferibles a aquellas que están en poder de otros; aquellas que son estables a aquellas que están mal aseguradas; aquellas que no pueden sernos quitadas a aquellas que pueden serlo".

Se valora lo normal como lo más frecuente, lo habitual como aquello que se acerca más a lo normal, apreciación en la cual interviene un tópico de cantidad.

Los tópicos de la cualidad son mejor comprensibles cuando se contesta la virtud del número. Así interpreta algunas expresiones de Calvino como la lucha de lo que constituye la verdad, garantizada por Dios, contra la multitud que yerra. Lo verdadero no puede sucumbir cualquiera que sea el número de sus adversarios: nos encontramos en presencia de un valor de orden superior, incomparable. Los protagonistas del tópica de la cualidad no pueden dejar de acentuar este aspecto: en el límite, el tópico de la cualidad desemboca en la valoración de lo único, que, como todo lo normal, es uno de los ejes de la argumentación.

Lo único está ligado a un valor concreto: lo que consideramos como un valor concreto nos parece único, y es lo que nos parece único lo que se convierte para nosotros en precioso. 
Considerar los seres como intercambiables, no ver lo que determina la especificidad de su personalidad, es devaluarlos. Hay filósofos como Martin Buber y Gabriel Marcel que se sublevan contra lo fungible, lo mecánico, lo universalizable. Dice Buber: "vale más todavía violentar un ser que se ha poseído realmente, que practicar una beneficencia necia dirigida a números sin rostro". Marcel dice que el valor de un encuentro con un ser nace de que ese valor es único en su género. Lo que es único no tiene precio, y su valor aumenta por el hecho mismo de que es inapreciable. También Quintiliano aconseja al orador que no se haga pagar su colaboración, por la razón de que "la mayoría de las cosas pueden parecer sin im. portancia por el hecho solo de que se les pone un precio".

El valor de lo único puede expresarse por su oposición a lo común, a lo banal, a lo vulgar. Estas características serían la forma depreciativa de lo múltiple opuesto a lo único. Lo único es original, se distingue, y por eso es notable, y complace incluso a la multitud. Es la valoración de lo único, o por lo menos de lo que parece sero, lo que constituye el fondo de las máximas de Graciano y de los consejos que él da al hombre de los tribunales. Es necesario evitar el repetirse; es necesario parecer inagotable, misterioso, no fácilmente clasificable; la cualidad única se convierte en un medio para obtener el sufragio del mayor número. Incluso el gran número aprecia lo que se distingue, lo que es raro y difícil de realizar. Lo más difícil, dice Aristóteles, es preferible a lo que lo es menos; pues apreciamos mejor la posesión de las cosas que no son fáciles de adquirir. Aristóteles no se contenta con enunciar el tópico. Esboza una explicación. Lo refiere a la persona y al esfuerzo. Lo raro concierne sobre todo al objeto, lo difícil concierne al sujeto, en tanto que agente. Presentar una cosa como difícil o rara es un medio seguro de valorarla.

Lo precario puede ser considerado como el valor cualitativo opuesto al valor cuantitativo de la duración; es correlativo de lo único, de lo original. Todo lo que está amenazado cobra un valor eminente.

Otro tópico citado por Aristóteles es el de la oportunidad: "cada cosa es preferible en el momento en que ella tiene la mayor importancia, por ejemplo, la au. sencia de tristeza o pesadumbre es más deseable en la vejez que en la juventud, pues tiene mayor importancia en la vejez".

El tópico de lo irreparable se presenta como un límite que viene a acentuar el tópico de lo precario: la fuerza argumentativa ligada a su evocación puede ser de un efecto fulminante. Ejemplo de esto lo tenemos en la célebre peroración de San Vicente de Paul al dirigirse a unas damas piadosas y mostrarles a los huérfanos que él protegia: "vosotras habéis sido sus madres según la gracia, desde que sus madres según la naturaleza los abandonaron. Ved ahora si queréis también abandonarlos para siempre... ; su vida y su muerte están en vuestras manos... : vivirán si continuáis otorgándoles vuestros cuidados caritativos; pero os lo declaro ante Dios, todos ellos estarán muertos mañana si los abandonáis".

Se puede valorar lo único én otro sentido: como lo opuesto a lo diverso, y entonces cobra la significación de norma y adquiere una dimensión cualitativa en 
oposición a la cuantitativa de lo diverso. Se opondrá la unicidad de la verdad a la diversidad de las opiniones.

Además de los cuantitativos y cualificativos, hay otros tópicos: del orden, de lo existente, de la esencia, y de la persona.

Los tópicos del orden afirman la superioridad de lo anterior sobre lo posterior, sea de la causa o de los principios, sea de la finalidad o de la meta. La superioridad de los principios, de las leyes sobre los hechos, sobre lo concreto, que parecen ser la aplicación de aquéllos, está admitida en el pensamiento no empirista. Lo que es causa es razón de ser de los efectos y, por consiguiente, es superior a ellos. Así en Plotino. Muchas grandes querellas filosóficas han girado sobre la cuestión de saber lo que sea anterior diferente de lo que sea posterior, para sacar de ello las conclusiones en cuanto al predominio de un aspecto de lo real sobre el otro. Las teorías finalistas, para valorar el fin, lo transforman en verdadera causa y origen de un proceso. El pensamiento existencial que insiste sobre la importancia de la acción dirigida hacia el porvenir, refiere el proyecto a la estructura del hombre $y$, por consiguiente, "busca siempre remontarse hacia lo originario, hacia la fuente".

Los tópicos de lo existente afirman la superioridad de lo que existe, de lo que es actual, de lo que es real, sobre lo posible, lo eventual o lo imposible. La utilización de los tópicos de lo existente supone un acuerdo sobre la forma de lo real a la que se los aplica: en un gran número de controversias filosóficas, aun admitiendo que se ha logrado el acuerdo sobre esos tópicos, uno se esfuerza en sacar de ellos un partido inesperado, gracias a un cambio de nivel en su aplicación o gracias a una nueva concepción de lo existente.

Entendemos por tópico de la esencia no la actitud metafísica que afirmaría la superioridad de la esencia sobre cada una de sus encarnaciones y que está fundada sobre un tópico del orden. Por el contrario, los tópicos de la esencia consisten en conceder un valor superior a los individuos en tanto que representantes bien caracterizados de esa esencia. Se trata de una comparación entre individuos concretos; y así atribuimos un valor a un conejo que presenta todas las cualidades de un conejo; será para nosotros un bello conejo. Se valora aquello que encarna de la mejor manera un tipo, una esencia, una función. Se podría fundar una ética o una estética sobre la superioridad de lo que encarna de mejor manera la esencia y sobre la obligación que hay de llegar a ello, sobre la belleza del hecho de llegar a ello. La moral del superhombre saca del tópico de la esencia todo su atractivo y prestigio.

Se examina después algunos de los tópicos derivados del valor de la persona, ligados a su dignidad, a su mérito, a su autonomía.

Sería interesante subrayar, en las diferentes épocas y en los diferentes ambientes, los tópicos que han sido admitidos más generalmente o que por lo menos parecen admitidos por el auditorio, tal y como éste se lo imagina el orador. Por otra parte, esta tarea sería delicada, porque los tópicos que se considera como indicutibles son utilizados, sin ser expresados. Por el contrario, se insiste sobre aquellos tópicos que se desea refutar o matizar en sus aplicaciones. 
Una misma finalidad puede ser realizada sirviéndose de tópicos muy diversos. Para acentuar el horror de una herejía o de una revolución se servirá o bien de los tópicos de la cantidad, mostrando que esta herejía acumula todas las herejías del pasado, o que esta revolución implica trastornos sobre trastornos más que ninguna otra; o bien se servirá de los tópicos de la cualidad mostrando que esa herejía preconiza una desviación totalmente nueva y esa revolución un sistema que antes nunca existió.

La situación argumentativa, esencial para la determinación de los tópicos a los cuales se recurrirá, es ella misma un complejo que comprende, a la vez, la finalidad a la cual se apunta y los argumentos con los cuales se tiene el riesgo de tropezar. Estos dos elementos están, por otra parte, íntimamente ligados; en efecto, la finalidad hacia la cual se apunta, incluso si se trata de soltar una acción bien definida, es al mismo tiempo la transformación de ciertas convicciones, la respuesta a ciertos argumentos, transformación y respuesta que son indispensables para el disparo de esta acción. Es así que la elección entre diferentes tópicos, de la cantidad o de la cualidad, por ejemplo, puede resultar uno u otro de los componentes de la situación argumentativa. Después se verá nítidamente cuál es al actitud del adversario, la que influye sobre esta elección. Otras veces se verá por el contrario el vínculo entre esta elección y la acción a disparar. Calvino utiliza a menudo tópicos de la cualidad. Esto es un carácter frecuente de la argumentación de aquellos que desean cambiar el orden establecido, frente a quienes desean mantenerlo, los cuales recurren a tópicos de la cantidad.

Un ejemplo mucho más general de pareja oposición lo encontramos en el esfuerzo hecho por los románticos para derribar ciertas posiciones del clasicismo: allí donde percibían que el clasicismo podría defenderse con la ayuda de los tópicos de la cantidad, el romanticismo recurría naturalmente a los tópicos de la cualidad. $\mathrm{Si}$ los clásicos apuntaban al auditorio universal, lo cual constituía una apelación a la cantidad, era normal que los románticos, cuya ambición se limitaba a menudo a persuadir un auditorio particular, recurriesen a los tópicos de la cualidad: lo único, lo irracional, la élite, el genio.

Si lo antiguo es valorado como habiendo subsistido durante más largo tiempo y encarnado una tradición, lo nuevo será valorado como original y raro.

Los tópicos de lo existente pueden ser referidos tanto a los tópicos de la cantidad, ligados a lo durable, a lo estable, a lo habitual, a lo normal, como también a los tópicos de la cualidad ligados a lo único y a lo precario. Se podría sostener que lo existente, como concreto, funda los tópicos de la cualidad, da su valor a lo único, y que lo existente, en tanto que real, funda los tópicos de la cantidad y da su sentido a lo durable $y$ a lo que se impone universalmente.

Los tópicos de la persona pueden ser fundados sobre los de la esencia, de la autonomía, de la estabilidad; pero también sobre la unicidad y originalidad de lo que se refiere a la persona humana.

A veces estos enlaces y las justificaciones de los tópicos son solamente ocasio- 
nales; pero sucede también otras veces que tal intento es el resultado de una toma de posición metafísica y caracteriza una visión del mundo.

A las virtudes clásicas de veracidad y de justicia, el romántico opone las del amor, de la caridad y de la fidelidad. Si los clásicos se adhieren a los valores abstractos, o por lo menos universales, los románticos preconizan los valores concretos y particulares; a la superioridad del pensamiento y de la contemplación, preconizada por los clásicos, los románticos opondrán la de la acción eficaz.

Lo que se llama habitualmente el sentido común consiste en una serie de creencias admitidas en el seno de una sociedad determinada y que sus miembros presumen que son compartidas por todo ser razonable. Pero al lado de esas creencias existen acuerdos propios de los participantes en una disciplian particular, sea ésta de naturaleza científica o técnica, jurídica o teológica. Estos acuerdos constituyen el cuerpo de una ciencia o de una técnica, y pueden ser el resultado de ciertas convenciones o de la adhesión a ciertos textos; y caracterizan a ciertos auditorios.

Esos auditorios se distinguen generalmente por el uso de un lenguaje técnico que les es propio. Es en las disciplinas formalizadas donde este lenguaje se diferencia al máximo de aquel que, por otra parte, los miembros de ese tuditorio utilizan en sus relaciones cotidianas y que comprenden en tanto que miembros de un auditorio más general. Pero incluso disciplinas tales como el Derecho, que utilizan muchos de sus términos técnicos tomándolos del lenguaje corriente, han podido parecer herméticas a los no iniciados. Por otra parte hay dominios de los cuales se dirá, según la concepción que uno se haga de los mismos, que son especializados o que escapan a toda convención o a todo acuerdo particular: éste es, de un modo eminente, el caso de la filosofía.

Se puede contraponer a una "filosofía popular", como la de Nietzsche, por ejemplo, las filosofías contemporáneas que suponen, todas, un conocimiento profundizado de la historia de la filosofía, con relación a la cual ellas son llevadas, de una manera o de otra, a pensarse ellas mismas.

Pero el filósofo que toma posición frente a esa historia de la filosofía, que le atribuye una significación determinada, y que desde luego debe admitir que su propia concepción responde a esta significación, ¿renuncia totalmente a dirigirse al auditorio universal? Claro que no.

EI ejemplo de la filosofía muestra bien que el problema de saber cuáles son los auditorios especializados es una cuestión de hecho, que debe ser resuelta en cada caso. Pero hay auditorios, tales como los de los juristas o de los teólogos, para los cuales esta cuestión está regulada gracias a consideraciones de orden formal: contrariamente al derecho natural y a la teología racional, el derecho positivo y la teología positiva, ligados por textos bien determinados, constituyen dominios de argumentación específica.

Los acuerdos de auditorios especializados pueden implicar definiciones particulares de ciertos tipos de objetos de acuerdo, por ejemplo con lo que es un hecho. Para el teólogo o el jurista se considera como un hecho no lo que se puede pre- 
tender por virtud del acuerdo del auditorio universal, sino aquello que los textos exigen o permiten tratar como tal hecho.

En las ciencias naturales contemporáneas, el hecho está subordinado, cada vez más, a la posibilidad de una medida, en el sentido amplio de este término. Dichas ciencias oponen una resistencia a toda observación que no pueda insertarse en un sistema de medidas.

Muy importante es el tema de las presunciones: el vinculo que une ciertos hechos a otros puede ser considerado por la ley como tan fuerte que la probabilidad de que éste sea acompañado por aquél equivale a la certidumbre judicial de aquél.

Las premisas de la argumentación consisten en proposiciones admitidas por los auditores. Cuando éstos no están ligados por reglas precisas que les obliguen a reconocer ciertas proposiciones, todo el edificio de quien argumenta no se funda más que sobre un hecho de orden psicológico, a saber la adhesión de los auditores. Muy a menudo el orador no puede contar, para sus presunciones, más que con Ia inercia psíquica y social que, en las conciencias individuales y en las sociedades, constituye lo análogo a la inercia en física. Se puede presumir, salvo prueba en contrario, que la actitud adoptada anteriormente -opinión expresada, conducta preferida - se continuará en el porvenir, sea por deseo de coherencia o gracia a la fuerza de lo habitual. Por el contrario, el cambio debe ser justificado; una decisión, una vez tomada no puede ser revocada más que por razones suficientes.

La justificación del cambio se hará sea por la indicación de una modificación objetiva, a la cual el sujeto ha debido adaptarse, sea por la indicación de un cambio en el sujeto, considerado como un progreso.

En derecho al demandante le corresponde la carga de la prueba, porque el derecho se conforma con la inercia; está concebido de modo de ratificar, salvo suficiente razón en contrario, los hechos tal y como ellos son. Es eficaz utilizar contra el interlocutor todo lo que pueda considerarse como una especie de confesión suya. En derecho, cuando sólo el interés de las partes está en juego, la confesión de una de las dos partes, como el acuerdo de las dos partes, suministra un elemento estable sobre el cual puede apoyarse el juez. Cuando se trata de materias en las cuales está interesado el orden público, entonces la confesión no tiene la misma fuerza probatoria, porque es el juez, y no las partes, quien entonces determina lo que debe considerarse como adquirido.

En lugar de basarse sobre los juicios del interlocutor, se utilizará a veces simples indicios de su confesión, o se tomará como base su silencio. El silencio puede ser interpretado, sea como el indicio de que no se ha encontrado ninguna objeción ni refutación, sea como el indicio de que el asunto es indiscutible excepto cuando se halla implicado un interés público. Ya Quintiliano dijo que lo que el adversario no niega constituye un elemento sobre el cual puede apoyarse el juez.

$\mathrm{El}$ uso dialéctico de preguntas y de respuestas tiende esencialmente a asegurar acuerdos explícitos que deben ser tomados como base; es una de las características de la técnica socrática. 
En este breve resumen no puedo tratar todas las observaciones sobre los tipos y los modos del silencio, que contiene la obra de Perelman y su colaboradora.

Las posibilidades de argumentación dependen de que cada uno esté dispuesto a conceder los valores que reconoce o los hechos con los que está de acuerdo. Por consiguiente, toda argumentación es una argumentación ad hominem. No obstante, se opone frecuentemente la argumentación ad hominen a la argumentación ad rem; refiriéndose la primera a la opinión y la segunda a la verdad o a la cosa misma. La argumentación ad rem corresponde a una argumentación que se pretende válida para toda la humanidad razonable. La argumentación que apunta al auditorio universal, la argumentación ad humanitatem, evitará, en la medida de lo posible, el uso de argumentos que sólo serían válidos para grupos particulares. Éste es el cuidado que se pone en la argumentación filosófica.

Sigue después un análisis de los diferentes tipos de argumentos ad hominem, tema tan variado como los auditorios a los cuales se dirigen. Pero aquí no se puede entrar en esos detalles.

Según Aristóteles, la petición de principio consiste en el hecho de postular lo que se quiere demostrar. Verifiquemos inmediatamente que, sobre el plano de la lógica formal, la acusación de petición de principio carece de sentido. En efecto, se podría pretender que toda deducción formalmente correcta consiste en una petición de principio, y el principio de identidad, que afirma que toda proposición se im. plica ella misma, sería la petición de principio puesta en forma. De hecho, la petición de principio, que no se refiere a la verdad, sino a la adhesión de los interlocutores a las premisas que se suponen, no es una falta de lógica, sino de retórica. La petición de principio consiste en un uso del argumento ad hominem, cuando éste no es utilizable, porque ella supone que el interlocutor se ha adherido ya a una tesis que uno se esfuerza precisamente en hacerle admitir. Todavía es preciso, además, que las dos proposiciones, el principio y la conclusión, que nunca son exactamente las mismas, estén suficientemente próximas la una de la otra para que la acusación de petición de principio esté justificada.

La petición de principio es una falta de la argumentación. Concierne a la argumentación ad hominem y la presupone, pues su dominio no es el de la verdad, sino el de la adhesión. Si se reconoce que es ilegítimo cometer peticiones de principio, es decir, fundar la argumentación sobre premisas que el auditorio rechaza, esto implica que uno puede servirse de aquellas que el auditorio admite. Cuando se trata de verdad, y no de adhesión, hay que proscribir el argumento ad hominem, pues en este caso la petición de principio es imposible.

Los acuerdos de los cuales dispone el orador, sobre los cuales puede tomar apoyo para argumentar, constituyen un dato, pero que es tan vasto y susceptible de ser utilizado de maneras tan diversas, que la forma de servirse de él presenta una importancia capital.

Sin embargo, precisemos que poder elegir entre los datos no implica que se pueda desdeñar los elementos que son inutilizados. Para cada auditorio existe un 
conjunto de cosas admitidas, que pueden influir sobre sus reacciones. Este conjunto es relativamente fácil de discernir cuando se trata de un auditorio especializado: será el corpus del saber reconocido por los cultivadores de una disciplina científica; será el sistema jurídico entero dentro del cual se inserta una decisión judicial. Excepto si se trata de un dominio formalizado, completamente aislable, este conjunto es fluido, está siempre abierto. Sus perfiles son particularmente vagos cuando se trata de un auditorio no especializado, aunque la elaboración filosófica pueda contribuir en ciertas épocas un poco a precisarlos. En todo caso constituye para cada auditorio un sistema de referencia que sirve para aquilatar argumentaciones.

El hecho de seleccionar ciertos elementos y de presentarlos al auditorio, im. plica ya su importancia y su pertinencia en el debate. En efecto, tal selección otorga a esos elementos una presencia, que es un factor esencial de la argumentación, que ha sido indebidamente olvidado en las concepciones racionalistas del razonamiento. La presencia obra de una manera directa sobre nuestra sensibilidad. Al contrario, tiene también mucha importancia al supresión de la presencia de un elemento en la argumentación. La utilización de los datos en vista de la argumentación no puede hacerse sin una interpretación, sin una elaboración conceptual que les da un sen. tido y los convierte en relevantes para la continuación del discurso.

En la medida en que la interpretación constituye una elección consciente o inconsciente, entre varios modos de significación, la interpretación puede ser distinguida de los datos que interpreta y opuesta a éstos.

Un problema grave de la interpretación consiste no sólo en la elección, sobre un plano bien definido, entre interpretaciones que parecen incompatibles, sino también en la elección del plano sobre el cual se llevará a cabo el esfuerzo de interpre. tación. Un mismo proceso puede ser descrito como el hecho de ajustar un eje, de ensamblar un vehículo, de ganarse la vida, o de favorecer la corriente de exportaciones. Por otra parte, un acto puede ser considerado en sí, cercenado todo lo posible, enfocado desde el aspecto más contingente, y aislado de la situación. Pero puede también ser interpretado como símbolo, como medio, como precedente, como jalón en una dirección.

La puesta en evidencia de una interpretación arroja en la penumbra a las demás. Lo esencial en un gran número de argumentaciones resulta de este juego de interpretaciones innumerables y de la lucha para, entre ellas, imponer alguna y descartar las demás.

Entre los antiguos, lo mismo si eran filósofos que juristas o teólogos, la interpretación se refería normalmente a textos. Son sobre todo los psicólogos modernos los que han insistido en la ubicuidad de la interpretación, la cual no está ausente ni siquiera al nivel de la percepción.

Conviene distinguir entre la interpretación de signos y la de indicios. Signo es un hecho susceptible de evocar otro fenómeno, en la medida en que es utilizado en un acto de comunicación. Por el contrario, el indicio permite evocar otro fenómeno de una manera, por así decirlo, objetiva, independientemente de toda intencionalidad. 
Liberado el pensamiento del sedicente sentido único de las palabras, se puede aceptar como interpretación correcta aquella que el orador atribuiria a sus propias palabras si él pudiese observar su propio discurso. El auditor encuentra este sentido buscando lo que le da satisfacción, criterio aplicable, porque el autor y el auditor tienen de común a la vez experiencias y modos de reaccionar. Así pues, la buena interpretación de una expresión sería aquella que el autor podría probar sobre la base del contexto.

Es siempre el contexto el que asigna a una palabra su significación, y es solamente por medio del contexto que nosotros podemos descubrir lo que ella cumple. Pero no se trata sólo del contexto puramente verbal, sino que el contexto comprende un conjunto de elementos de la situación real.

La interpretación de un texto está influida por las tesis previamente admitidas, las cuales pueden variar según los intérpretes.

El arreglo de los datos en vista de la argumentación consiste no sólo en la interpretación de los mismos, en la significación que se les conceda, sino también en la presentación de ciertos aspectos de tales datos, gracias a los acuerdos subya.centes en el lenguaje del cual se sirve uno. Esta elección se manifiesta de la manera más aparente por el uso de los epítetos. Éstos consisten en seleccionar una cualidad que se pone por delante, y que debe completar nuestro conocimiento del objeto. Pero, muchas veces, hay la posibilidad de usar epítetos no sólo diferentes, sino incluso opuestos en cuanto a su sentido y a su alcance. Calificar a Orestes de "asesino de su madre" o "vengador de su padre" es elegir un punto de vista cuyo carácter tendencioso se percibe porque se ve inmediatamente cómo podría ser corregido. Pero no todos los epitetos se presentan como una elección entre dos puntos de vista que exigen, por así decirlo, de ser completado el uno por el otro. Con la mayor frecuencia sucede que los aspectos de una realidad se sitúan sobre planos diferen. tes, y que una visión más completa de lo real no puede consistir sino en una multiplicación progresiva de aspectos hacia los cuales se atrae la atención.

La calificación de los datos, la inserción de los mismos en las clases constituyen los dos aspectos de una misma actividad, enfocada lo mismo en comprehesión que en extensión, y que es la aplicación de nociones al objeto del discurso. Estas nociones, y lo mismo su empleo, mientras no susciten dificultades, se presentan igualmente como datos con los cuales se cree poder contar, y con los cuales se cuenta en efecto eficazmente. Pero la índole de este acuerlo, la conciencia de su dimensión precaria, de sus limites y también de las posibilidades argumentativas que él ocul. ta, pueden interpretarse diversamente.

El paso unívoco de la palabra a la idea que aquélla representaría es, a los ojos de los antiguos teóricos, un fenómeno que se desprende del buen uso del lenguaje. Se supone además que esta idea puede ser determinada con precisión recurriendo a otras ideas, las cuales a la vez son expresadas por términos unívocos, o que pueden ser objeto de una intuición racional. El lenguaje artificial de los matemáticos suministra a muchos buenos espíritus un ideal de claridad y de univocidad 
que las lenguas naturales, menos elaboradas, deberían esforzarse por imitar. Toda ambigüedad, toda confusión son, en esta perspectiva, consideradas como imperfecciones eliminables no sólo en principio, sino también de hecho. La univocidad y la precisión de sus términos harían del lenguaje científico el instrumento mejor para las funciones de la demostración y de la verificación; y éstos son los caracteres que se querría imponer a todo lenguaje.

Pero ¿puede decirse que el lenguaje científico esté exento de toda ambigüedad? Se ha desarrollado una discusión, después de un artículo de Black, en una revista consagrada a la filosofía de las ciencias, en la cual Benjamin llega a la conclusión de que las ideas vagas son parte integrante de la ciencia, y que toda teoría de la significación que las niegue no es una teoría de la ciencia.

Parece que resulta que se ha reconocido que una noción no puede ser considerada como unívoca más que si su campo de aplicación está enteramente determinado, lo que no es posible sino en un sistema formal del cual se ha podido eliminar toda dimensión imprevista; la noción de "alfil" en el juego de ajedrez satisface esta condición. Pero no es lo mismo cuando se trata de nociones elaboradas en el seno de un sistema científico o jurídico y que deben aplicarse a acontecimientos futuros cuya naturaleza no siempre puede ser precisada completamente. Para tomar en cuenta esta situación, Waismann, en un artículo notable, nos pide que abandonemos la idea de que las nociones científicamente utilizables pueden ser reducidas a unos sense-data, pues su uso supone una textura adaptable a las exigencias de una experiencia futura.

En la medida en que las experiencias futuras y la manera de examinarlas no sean por entero previsibles, es indispensable concebir los términos más precisos como rodeados de una franja de indeterminación suficiente para que esos términos puedan aplicarse a lo real. Una noción perfectamente clara es aquella de la cual se conocen todos los casos de aplicación y que no admite un nuevo uso que sería un uso imprevisto: sólo un conocimiento divino o un conocimiento convencionalmente limitado es adecuado a una exigencia tal.

Por estas razones no es previsible aproximar el rigor del derecho al de aquel de la matemática. En efecto, el juez no puede, al modo del lógico formalista, limitar una vez por todas el campo de aplicación de su sistema. Arriesga incurrir en culpabilidad por denegación de justicia si rehusa juzgar "a pretexto de silencio, de oscuridad o de insuficiencia de la ley" (artículo cuarto del código de Napoleón). Hace falta pues poder juzgar si la disposición legal invocadá es o no aplicable a la situación, incluso si esta última no ha sido prevista por el legislador. Esto obliga a tomar una decisión motivada en cuanto a la manera, según la cual precisará de una u otra categoría jurídica.

La flexibilización y el endurecimiento de las nociones es una técnica adoptada cuando la apreciación que las concierne debe ser, por lo menos en parte, el resultado de la argumentación. Por el contrario, cuando el valor designado por la noción está netamente establecido y es previo a la argumentación, se servirá de otra técnica 
que influye sobre la extensión de las nociones. Esta otra técnica consiste, simplemente, en ampliar o en restringir el campo de una noción de manera que ella englobe o no ciertos seres, ciertas cosas, ciertas ideas, ciertas situaciones. Por ejemplo, se extenderá el campo del término peyorativo, "fascista" para englobar en él a ciertos adversarios; mientras que se restringirá la extensión del término "democrático", en sentido valorativo, para excluir a los enemigos. Inversamente se limitará el sentido de la palabra fascista para excluir a los amigos que sostienen algunas de sus tesis, y se extenderá el sentido de la palabra "democrático" para incluirlos. Esta técnica es usada no solamente en política. Se la encuentra también en las controversias científicas. Así Claparède verificaba que cuando el asociacionismo fue abandonado por los psicólogos, éstos se criticaban los unos a los otros tratándose de asociacionistas, ampliando progresivamente esta noción para poder englobar dentro de ella al adversario.

Adviértase que la "significación emotiva" es parte integrante de la significación de la noción; no es una adición suplementaria, adventicia, extraña el carácter simbólico del lenguaje.

En la argumentación hay que atribuir un papel eminente a la presencia, a la puesta en evidencia, para permitirles ocupar el primer plano de la conciencia, de ciertos elementos sobre los cuales el orador desea centrar la atención. Incluso antes de argumentar a partir de ciertas premisas, es esencial que el contenido de éstas se destaque sobre el fondo indiferenciado de los elementos de acuerdo disponibles: esta elección de las premisas se confunde con su presentación. Una presentación eficaz, que impresione la conciencia de los auditores, es la esencial no solamente en toda argumentación que apunta a la acción inmediata, sino también en aquella que apunta a orientar el espíritu de una cierta manera, a hacer prevalecer ciertos esquemas interpretativos, a insertar los elementos de acuerdo dentro de un cuadro que los haga significativos y les confiera el lugar que les corresponde en un conjunto.

Hay que rehusarse a separar en el discurso la forma y el fondo, a estudiar las estructuras y las figuras de estilo independientemente de la finalidad que ellas deben cumplir en la argumentación. Es verdad que determinadas maneras de expresarse pueden producir un efecto estético, ligado a la armonía, al ritmo, a otras cualidades puramente formales, y que ellas pueden tener una influencia argumentativa por la admiración, el gozo, la excitación, los altibajos de la tensión que ellas provocan, sin que esos diversos elementos sean analizables en función directà de la argumentación. Pues bien Perelman excluye, sin embargo, el estudio de esos mecanismos, a pesar de su importancia incontestable en la acción oratoria.

Lo que interesa en el examen de la forma del discurso, en la medida en que la creamos distinguible de su materia, son los medios gracias a los cuales una cierta presentación de los datos sitúa el acuerdo a un cierto nivel, lo imprime con una cierta intensidad en las conciencias, pone de relieve ciertos aspectos. Pensando en las variaciones de forma, en las presentaciones diversas de un cierto 
contenido - que, por otra parte, no es enteramente el mismo cuando ha sido presentado de otra manera-, será posible dar con la pista que nos permita elegir la forma más conveniente.

Todo discurso está limitado en el tiempo y lo mismo puede decirse de todo escrito que se dirige a terceros. Sean cuales fueren las razones de esta limitación, la forma del discurso debe tenerla en cuenta. Quien pronuncia un discurso, que apunta a la persuasión, debe administrar su tiempo y la atención de los auditores. Es normal que conceda a cada parte de su exposición un lugar proporcional a la importancia que él querría ver que se le atribuye en la conciencia de aquellos que lo escuchan.

La técnica de la acumulación, de la insistencia, está frecuentemente ligada a otra técnica, la de la evocación de los detalles, hasta el punto de que a veces las dos son indistinguibles.

Al lado de las hipótesis científicas que sirven para la invención, encontramos hipótesis argumentativas. En uno de sus discursos, Demóstenes evoca la hipótesis en la cual Esquino sería el acusador, Felipe el juez y él mismo el acusado. Imagina, en esta situación ficticia, el comportamiento, las reacciones de cada uno, para deducir de ello lo que debe ser el comportamiento y las reacciones en la situación real. A veces, por el contrario, la hipótesis está descrita en todos sus detalles, para combatirla violentamente.

Para crear la emoción, es indispensable la especificación. Las nociones generales, los esquemas abstractos no operan apenas sobre la imaginación. Un audi. torio que había quedado insensible ante las proposiciones generales sobre la carnicería que caracterizó una batalla, ese auditorio se emocionó hasta las lágrimas por un pequeño detalle relativo a la muerte de dos jóvenes.

La aproximación entre lenguaje ordinario e ideas recibidas no es fortuita: el lenguaje ordinario es, en sí mismo, la manifestación de un acuerdo, de una comunidad.

La manera según la cual formulamos nuestro pensamiento da a conocer algunas de sus modalidades, que modifican la realidad, la certeza o la importancia de los datos del discurso. Pertenece a este tema la cuestión sobre las modalidades, en el sentido técnico del lingüista. Generalmente se admite que esas modalidades son cuatro: la asertiva, la prescriptiva, la interrogativa y la optativa.

La modalidad asertiva conviene a toda argumentación. No hay necesidad de hablar de ella.

La modalidad prescriptiva se expresa, en nuestras lenguas, por el imperativo. Contrariamente a las apariencias, esta modalidad prescriptiva no tiene fuerza persuasiva. Todo su poder viene de la influencia dominante de la persona que ordena sobre la ordenada: es una relación de fuerzas que no implica ninguna adhesión. Cuando la fuerza real está ausente, o cuando no se enfoca su utilización, el imperativo toma el acento de un ruego. A causa de esta relación implicada por la forma imperativa, ésta es muy eficaz para aumentar el sentimiento 
de presencia. El reportero de un concurso deportivo, en la radio, prescribe a veces a los jugadores que hagan esto o aquello. Estos imperativos son oídos por los jugadores, no se refieren a los auditores, pero con todo al comunicar indirectamente juicios sobre los jugadores, dan a la escena un alto grado de presencia, debido a que el que habla parece participar en la acción que describe.

La modalidad interrogativa tiene una enorme importancia retórica. La pregunta supone un objeto al cual se refiere y sugiere que hay un acuerdo sobre la existencia de este objeto. Responder a una pregunta, es confirmar este acuerdo implícito: los diálogos socráticos nos enseñan mucho sobre la utilidad y sobre los peligros de esta técnica dialéctica. El uso de la interrogación apunta a veces a una confesión sobre un hecho real desconocido por aquel que pregunta, pero del cual se presume la existencia así como la de sus condiciones. "¿Qué hizo usted aquel día en tal lugar?" Esto implica ya que el interpelado se encontraba en un cierto momento en el lugar indicado; si él responde, marca su acuerdo sobre este punto. Pero muy a menudo la interrogación, con todo y ser real, no apunta tanto a aclarar a quien interroga como más bien a acorralar al adversario sumiéndole en contradicciones. Hay preguntas muy frecuentes que no son sido una forma hábil para poner un cebo a razonamientos, especialmente usando de la alternativa, o de la división con la complicidad, por asi decirlo, del interlocutor que se compromete con sus respuestas a adoptar este modo de argumentación.

Los presupuestos implícitos en ciertas preguntas hacen que la forma interrogativa pueda ser considerada como un procedimiento bastante hipócrita para expresar ciertas creencias. Diciendo " $¿ Q u e ́$ ha podido conducir a los alemanes a desencadenar últimamente tantas guerras?", se sugiere a menudo que las respuestas que podrían ocurrírsele a uno deben ser rechazadas; y que en el fondo quien hace la pregunta tiene ya la contestación la cual equivale a una especie de acusación contra los alemanes.

Otras veces la interrogación sería, segín Wittgenstein, un juicio en una frase como ésta: "¿no es espléndido el tiempo hoy?" A veces una pregunta (cuya respuesta está implícita) puede servir para contestar otra pregunta. Así, Gide contesta a la pregunta "¿qué piensa usted de Rusia?" con otra pregunta, “¿pero es que puede usted preguntármelo?".

El empleo de los tiempos del verbo permite también actuar sobre el auditorio. En varias lenguas neolatinas se puede decir que el pretérito perfecto expresa lo irrefragable, lo hecho; el imperfecto es el tiempo de lo transitorio; el presente expresa lo universal, la ley, lo normal. El presente es el tiempo de la máxima, de la sentencia, es decir, de aquello que está considerado como actual siempre, como jamás periclitado. El presente tiene la propiedad de dar más fácilmente el sentimiento de presencia.

La modalidad optativa es quizá aquella que se presta mejor a la.expresión de normas. La acción del deseo expresa una aprobación e indirectamente una norma, por lo cual se aproxima al imperativo que expresa un ruego o una súplica. 
La forma bajo la cual son presentados los datos no está destinada solamente a producir efectos argumentativos relativos al objeto del discurso; puede también ofrecer un conjunto de caracteres relativos a la comunión con el auditorio.

Todo sistema lingüistico implica reglas formales de estructura que ligan a los usuarios de este sistema, pero la utilización de éste se acomoda a diversos estilos, a fórmulas particulares, características de un determinado medio, del lugar que se ocupa en éste, y de una cierta atmósfera cultural.

Se conoce el papel que desempeña en los vocabularios la diferenciación de los medios. Se sabe que existen en ciertas sociedades lenguas reservadas a los nobles o a los dioses: el uso de términos arcaicos, de dialectos, de jergas.

Puede distinguirse entre dos grandes estilos en la trasmisión del pensamiento: el de las sociedades democráticas y el de las sociedades jerarquizadas. El lenguaje en una socidad igualitaria pertenece a todo el mundo y evoluciona libremente. Por el contrario, el lenguaje se cuaja o se coagula en una sociedad jerarquizada. En ella las expresiones y las fórmulas se convierten en rituales: y son escuchadas con un espiritu de comunión y sumisión total.

Desde la Antigüedad se ha reconocido la existencia de ciertos modos de expresión que se salen de lo ordinario, cuyo estudio se solía incluir en los tratados de retórica. A tales modos se les llamaba figuras de retórica.

El empleo de ciertas figuras determinadas se explica por las necesidades de la argumentación. La figura retórica es una estructura que no se emplea habitualmente, cuyo uso tiene una dimensión diríamos excepcional.

Después de haber resumido la segunda parte de este libro, que se ocupa del punto de partida de la argumentación, habré de limitarme a indicar el contenido de la tercera parte de esta obra, que versa sobre las técnicas argumen. tativas; y analiza los argumentos casi lógicos, que presentan la apariencia de demostraciones lógicas o matemáticas, pero que no lo son, porque, en el fondo, se trata de razonamientos argumentativos; los argumentos basados sobre la estructura de lo real; los enlaces que fundan la estructura de lo real; la disociación de las nociones; y la interacción de los argumentos.

En la "Conclusión", los autores dicen que en el presente libro se han limita. do tan sólo a esbozar algunos de los temas pertenecientes a la argumentación, tocando muchos otros puntos nada más que tangencialmente, de pasada. "Cada uno de los puntos cuyo examen ha sido apenas esbozado merecería un estudio profundo. Las diversas especies de discurso, su variación en función de las disciplinas $y$ de los auditorios; la manera según la cual las nociones se modifican y se organizan; la historia de esas transformaciones; los métodos y los sistemas a los cuales ha podido dar naciomiento de adaptación de conjuntos conceptuales a problemas de conocimiento; y tantas otras cuestiones que apenas han sido esbozadas, presentan al estudio de la argumentación un terreno de investigación de una riqueza incomparable."

Todas estas cuestiones han sido hasta el presente o bien enteramente olvi- 
dadas o bien estudiadas con un método y con un espíritu extraños al punto de vista retórico. En efecto, la limitación de la lógica al examen de las pruebas que Aristóteles calificaba de analíticas y la reducción a éstas de las pruebas dialécticas —cuando se ligaba algún interés a su análisis-, han eliminado del estudio del razonamiento toda referencia a la argumentación. Esperamos que este tratado provocará una reacción saludable, y que su mera presencia impedirá en el porvenị la reducción de todas las técnicas a la prueba de lógica formal, así como el ver en la razón nada más que una facultad calculadora.

"Si una concepción estrecha de la prueba y de la lógica ha traído consigo una concepción angosta de la razón, la ampliación de la noción de prueba y el enriquecimiento de la lógica que resulta de aquélla no pueden sino reaccionar, a su vez, sobre la manera según la cual está concebida nuestra facultad de razonamiento. Por eso querríamos terminar con consideraciones que rebasan, por su generalidad, una teoría de la argumentación, pero que le suministrar un cuadro que pone en relieve su interés filosófico.

"Combatimos las oposiciones filosóficas, tajantes o irreductibles, que nos presentan los absolutismos de toda especie: el dualismo de la razón y de la imaginación; el de la ciencia y de la opinión; el de la evidencia irrefregable y de la voluntad engañosa; el de la objetividad universalmente admitida y de la subjetividad incomunicable; el de la realidad que se impone a todos y de los valores puramente individuales.

"No creemos en revelacioies definitivas e inmutables cualquiera que sea su naturaleza o su origen; los datos inmediatos y absolutos, que se llaman sensaciones, evidencias racionales o intuiciones místicas, serán apartados de nuestro arsenal filosófico. Ni que decir tiene que este rechazo no implica que separemos el efecto sobre nuestras opiniones de la experiencia o del razonamiento, sino que no haremos nuestra la pretensión exorbitante de erigir en datos definitivamente claros y firmes, ciertos elementos del conocimiento, idénticos en todos los espiritus normalmente constituidos, independientes de las contingencias sociales históricas, fundamento de verdades necesarias y eternas.

"Nuestra posición será muy diferente. En lugar de fundar nuestra filosofia sobre verdades definitivas e indiscutibles, partiremos del hecho de que unos hombres y unos grupos humanos se adhieren a toda clase de opiniones con una intensidad variable, que sólo la puesta a prueba permite conocer. Las creencias de las cuales se trata no son siempre evidentes, y su objeto consiste raramente en ideas claras y distintas. Las creencias admitidas generalmente quedan largo tiempo como implícitas y no formuladas, pues, lo más frecuente es que en ocasión de un desacuerdo en cuanto a las consecuencias que resultan de aquellas creencias, se plantea el problema de su formulación y de su determinación más precisas.

"El sentido común opone regularmente los hechos a las teorías, las verdades a las opiniones, lo que es objetivo a lo que no lo es, señalando de ese modo 
aquellas opiniones que es necesario preferir a otras, tanto si esta preferencia está fundada o no sobre criterios generalmente aceptados. Hay quienes admiten tan solamente como pruebas válidas el raciocinio de tipo matemático o la cons. tatación empírica, pero con ello angostan terriblemente el ámbito del pensamiento."

Por el contrario si hay problemas esenciales, trátase de cuestiones morales, sociales, jurídicas o políticas, filosóficas o religiosas, que escapan por su propia índole a los métodos de las ciencias matemáticas y naturales no parece razonable apartar con desprecio todas las técnicas de razonamiento propias de la deliberación, de la discusión, en una palabra, de la argumentación. Es demasiado fácil descalificar como "sofistiquerias" todos los razonamientos que no se adecuan a las exigencias de la prueba que Pareto llama lógico-experimental. Si se debiera considerar como razonamiento engañoso toda argumentación de esta especie, la insuficiencia de pruebas "lógico-experimentales" dejaría a dominios esen. ciales de la vida humana el campo enteramente libre a la sugestión y a la violencia. Quien pretenda que lo que no es válido objetivamente y de modo indiscutible pertenece sólo al ámbito de lo subjetivo y de lo arbitrario, hiende un foso insalvable entre el conocimiento teórico, el único supuestamente válido y la acción práctica cuyas motivaciones serían enteramente irracionales. En una tal perspectiva, la práctica ya no puede ser razonable, pues la argumentación crítica se con. vierte en incomprensible. En efecto, solamente los dominios de los cuales se ha eliminado toda controversia pueden pretender una cierta racionalidad. Cuando hay controversia y los métodos lógico-experimentales no pueden restablecer el acuerdo de los espíritus, entonces nos encontraremos en el campo de la deliberación, de la discusión, de la argumentación.

En la medida en que sea posible discernir, en la práctica argumentativa, los enunciados referentes a hechos por una parte $y$, por otra parte, los enunciados relativos a valores, nunca tenemos asegurada esta distinción, porque ella resulta de acuerdos precarios de intensidad variable, a menudo todo ello implícito. Para poder distinguir netamente dos especies de juicios, haria falta poder proponer criterios que permitiesen identificarlos, criterios que deberían escapar a toda controversia $y$, más particularmente, sería necesario un acuerdo concerniente a los elementos lingüísticos sin los cuales ningún juicio es formulable.

Para que los juicios de realidad suministren un objeto indiscutible de un saber común, sería necesario que los términos que contienen estuvieran desprovistos de toda ambigüedad, sea porque hubiese medio de conocer su verdadero sentido, sea porque una convención unánimemente admitida suprimiera toda controversia sobre este punto. Esas dos eventualidades, que son las del realismo y del nominalismo en materia de lingüística, son ambas insostenibles, porque ellas consideran el lenguaje como un reflejo de lo real o una creación arbitraria de un individuo, y olvidan un elemento esencial, el aspecto social del lenguaje, instrumento de comunicación y de acción sobre los demás. 
Todo lenguaje es el de una comunidad, tanto si se trata de una comunidad unida por vínculos biológicos, o por la práctica de una disciplina o de una técnica comunes. Los términos utilizados, sus sentidos, sus definiciones, no se comprenden más que en el contexto suministrado por los hábitos, los modos de pensar, los métodos, las circunstancias exteriores, y las tradiciones comunes de los usuarios. Una desviación del uso debe ser justificada, y el realismo, lo mismo que nominalismo, no constituyen en lo que atañe a este punto nada más que dos tentativas, diametralmente opuestas, ambas ligadas a filosofías del lenguaje parejamente insuficientes.

La adhesión a ciertos usos lingüísticos es normalmente la expresión de tomas de posición, explícitas o implícitas, que no son ni el reflejo de una realidad objetiva ni la manifestación de un arbitrio individual. El lenguaje forma parte de las tradiciones de una comunidad, $y$, como ellas, no se modifica de un modo revolucionario, como no sea en un caso de inadaptación radical a una situación nueva: por lo demás, su transformación es lenta e insensible. Pero un acuerdo sobre el uso de los términos, como todo lo que se refiere a la concepción de lo real y a la visión del mundo, incluso si es indiscutido, no es indiscutible: está ligado a una situación social e histórica, la cual condiciona fundamentalmente toda distinción que se quisiera establecer entre juicios de realidad y juicios de valor.

Querer trascender esas condiciones sociales e históricas del conocimiento transformando ciertos acuerdos de hecho en acuerdos de derecho, no es posible más que gracias a una toma de posición filosófica que no se concibe, si ella es racional, nada más que como consecuencia de una argumentación previa. La práctica y la teoría de la argumentación son, en nuestra opinión, correlativas de un racionalismo crítico, que trasciende la dualidad entre juicios de realidad y juicios de valor, y suministra tanto los unos como los otros solidarios de la personalidad del sabio o del filósofo, responsable de sus decisiones en el dominio del conocimiento como también en el de la acción.

Sólo la existencia de una argumentación que no sea ni coercitiva ni arbitraria, concede un sentido a la libertad humana, condición del ejercicio de una elección razonable. Si la libertad no fuera nada más que adhesión necesaria a un orden natural previamente dado, ella excluiría todas las posibilidades de elección: si el ejercicio de la libertad no estuviera fundado sobre razones, toda elección sería irracional y se reduciría a una decisión arbitraria obrando dentro de un vacío intelectual. Gracias a la posibilidad de una argumentación, que suministra razones, pero razones no coercitivas, es posible escapar al dilema: adhesión a una verdad objetivamente y universalmente válida, o recurso a la sugestión y a la violencia, para hacer admitir sus opciones y sus decisiones. Lo que una lógica de los juicios de valor se ha esforzado en vano en suministrar, a saber, la justificación de la posibilidad de una comunidad humana dentro del dominio de la acción, cuando esta justificación no puede ser fundada sobre una realidad o una verdad objetiva, entonces la teoría de la argumentación contribuiría a elaborarla, y esto 
a partir de un análisis de esas formas de razonamiento que, aunque indispensables en la práctica, han sido olvidadas, a partir de Descartes, por los lógicos y los teóricos del conocimiento.

Luis Recaséns Siches 